\title{
DESAFÍOS PARA LA UNIVERSIDAD EN LOS NUEVOS TIEMPOS
}

(Conferencia dictada por Marcos García de la Huerta en el Salón de Honor del ex-Congreso Nacional, en Santiago, el 12 de septiembre de 2019, con ocasión de la promulgación de la nueva Ley de Educación Superior. Asisten parlamentarios, rectores de las universidades estatales e invitados especiales)

\section{Distinguido auditorio}

$\mathbb{R A}$ Pedro de Valdivia, al fundar Santiago, pensó en un cerro y un río; O’Higgins pensó en un ejército y una armada al echar las bases del Estado, y Andrés Bello al fundar la nación cívica, pensó en un Código y una Universidad. Las tres instalaciones responden a imperativos distintos: vigilar, resguardar y asear, en un caso; disuadir, cuidar y defender, en otro; instaurar el gobierno de las leyes y formar al ciudadano sapiente y consciente, en el tercer caso. Ante las urgencias y apremios del presente, estos asuntos parecen remotos, pero los comienzos son momentos de construcción de instituciones, de creación de identidad. Las sociedades crecen desde sus raíces, y lo que ahora está en lisa es una desinstitucionalización que nos amenaza en lo más entrañable y la universidad no está a salvo. Recordar es condición del curar, y la autocomprensión, que Freud enseñó como método de la cura, aplica también de otro modo en la autocomprensión ético-política del colectivo.

Por lo demás, nada está hoy asegurado, ni la continuidad del mundo ni la de nuestra residencia terrestre. Es insólito, pero es así, y la ciencia tiene algo que ver con eso: no es casual que sea protagonista en todas las distopías, también en las utopías, es cierto. Pero Nietzsche, que tenía un tercer ojo, que veía a distancia, advirtió a fines del siglo XIX: "un siglo de barbarie se avecina y las ciencias estarán a su servicio". Nada garantiza que las cosas ahora irán para mejor, más bien crece la sensación y el temor de que el futuro, si es que lo hay, será peor. Y cuando todo es incierto, ninguna pregunta está prohibida.

¿Qué hemos hecho con lo que hubo y se creó? Al río, lo convertimos en cloaca, a las instituciones de la defensa, las taparon de billetes y las dejaron sin control: no se necesita nada más para malearlas; y a la universidad, se le ha querido imponer autofinanciamiento y gratuidad, dos exigencias imposibles por incompatibles, como fuego helado o círculo cuadrado. A eso se agrega el difundido anhelo de que lo bueno y lo mejor no cuesten nada. Si los fundadores se hubieran preguntado “¿Se financiará?” nunca habría nacido este país, que se sostiene vendiendo las riquezas de su suelo, que es como mantener una casa vendiendo los muebles.

Tuvimos la suerte de contar con la mejor cabeza que produjo el siglo XIX en esta parte del mundo. Pertenecía a una generación a los que el amor a la libertad les golpeó como un relámpago; Andrés Bello respondió en sus propios términos y perspectiva, la de un hijo del siglo XIX, como legislador ilustrado. 
Venezuela, su patria de origen, se debatía en una guerra civil crónica, y él se exiló en Londres donde a duras penas se "ganaba" la vida, como se dice, aunque en realidad la perdía para el mundo. Allí le encontró un emisario del que presuntuosamente se llamaba "gobierno de Chile", cuando el Estado nación era aún Estado ficción y "Chile" se confundía con el Valle Central. Bello aceptó la invitación, felizmente, y abandonó la gran urbe cosmopolita para avecindarse en un villorrio de unos cien mil habitantes, que no era más que eso Santiago hacia 1830; y aquí llegaría a ser el que siempre será. Entendió la universidad como una institución que podía dar entidad civil a la joven República y nuevos aires a la ruda existencia en ese fértil valle. Lo llamamos así, en lugar de hablar de "nación", porque natio es lo que nace, y la nación, entonces, estaba aún por nacer. La "rudeza" se refiere al áspero trabajo que procura los medios de subsistencia, pero no basta para dar un sentido a la vida en común. Todo estaba por hacer: había que crear un marco legal, las instituciones educativas, los medios de prensa, en una palabra, los órganos de la libertad. La voz de la pólvora recién se acallaba y había que traducir lo conquistado en los campos de batalla en el lenguaje de las reglas y las instituciones, sobre todo en el hábito de mantener el conflicto, inherente al ser social, en el registro de la palabra. La universidad, el espacio de la libertad por excelencia, sirvió de modelo a las otras academias fundadas en el siglo XIX y, a la postre, se convirtió en algo así como la estrella de la bandera; y Bello, junto a Portales, en el héroe civil del Estado. ¿Será casual que fuese más de uno el sujeto de la fundación, contraviniendo a Maquiavelo, quien suponía que debe ser uno solo? El heroísmo es "político", es decir, plural, afirma Patrice Vermeren, y lo define como la capacidad de iniciar algo cuyo resultado es imprevisible, estableciendo así una nueva sociedad en la cual las figuras del héroe y del legislador coinciden...Pero si "el héroe es el verdadero sujeto de la modernidad" (Como dice Walter Benjamin citando a Baudelaire), ¿no es la posibilidad del heroísmo en la prosaica sociedad moderna y posrevolucionaria la llave de salida del siglo XIX? ${ }^{1}$

A juzgar por la vastedad casi inverosímil de sus intereses intelectuales y las funciones que desempeñó, Bello es una suerte de "intelectual orgánico de la República conservadora" ${ }^{2}$. El testimonio de Ramiro de Ávila puede dar una idea de su abrumadora presencia pública: "Hacia 1850, a los 70 años de edad, Bello desempeñaba al mismo tiempo las funciones de rector, subsecretario de relaciones exteriores y consultor de gobierno, senador, redactor de El Araucano; además, trabajaba intensamente en la elaboración del Código Civil y en sus obras de derecho, de filología y sus producciones literarias". " "Además de ser la cumbre del castellano durante el siglo XIX, según [la Enciclopedia Británica, una obra] redactada con la documentación y sobriedad propia

1 Patrice Vermeren, La república independiente, el poder constituyente y el héroe de la emancipación, en Revista de filosofía Vol. 67, pp. 65-85, Año 2011.

2 El intelectual orgánico de la República conservadora es el título del artículo que escribí en el libro Andrés Bello. Filosofia pública y política de la letra. Fondo de Cultura, México, Santiago, Buenos Aires, 2013.

3 Alamiro de Ávila, Mora y Bello en Chile. Eds. de la Universidad de Chile, Santiago, 1982. 
de la mejor prosa académica, que aborrece la lisonja y la exageración..., Bello habría sido "el padre intelectual de América del Sur"4.

Miguel Orellana propone una hipótesis audaz y seductora, aunque no se la comparta, posee un gran poder hermenéutico: la universidad no nace de la república sino al revés: "la libertad, en todas partes, nace de la educación", dice él. Significa superponer al mito del "Estado creador" de Mario Góngora, el de la universidad creadora. Sin embargo, la primera Academia nació como un margen de la ciudad y como un refugio frente a la intolerancia. Abrumado ante la injusticia de la muerte de Sócrates, Platón pensó en un espacio de pensamiento libre -un borde de las refriegas de la polis-, y creó la Academia de Atenas, la primera entre las miles que posteriormente han contribuido a hacer más tolerable y menos oscuro el mundo. Una de las acusaciones contra Sócrates, fue la de "corromper a la juventud”. Pero ¿qué significa corromper? Ante todo, es desviar algo de su función propia y extraviarla o malearla. A Sócrates, se le condenó por cuestionar la fe de la tradición y enseñar a cuestionar, es decir, se le condenó por pensar. El pensamiento "corrompe" en el sentido que remueve convicciones y el lenguaje de tradición, altera los lazos éticos que dan cohesión al colectivo. Por eso el pensamiento representa un riesgo, pero al mismo tiempo, una avanzada. Cada vez que se cierran las sociedades y se hacen más opresivas de lo que espontáneamente tienden a ser, el pensamiento se convierte en algo incómodo y se le tolera en el mismo sentido que esta palabra tiene en las casas de tolerancia (Hegel).

El caso es, que las universidades recién creadas en el Nuevo Mundo, en tiempos de Bello, desde México hasta el extremo sur, se llamaron todas "autónomas" o "nacionales" cuando no adoptaban el nombre de la república misma, como en nuestro caso. Esto se puede entender en el sentido que, en el ámbito público, la universidad es el verdadero suelo, la patria de la libertad, y que ser pensante y ser libre es casi equivalente.

¿La verdad y el saber hacen libre? ¿Es posible compartir la creencia de que el saber y la ciencia liberan?

"La ciencia no piensa" (Heidegger) Esta manida frase no dice otra cosa sino que pensar y conocer son distintos; afirmar que la ciencia no piensa es equivalente a sostener que la filosofía no es "científica", y esto no implica ningún menoscabo, porque ser sapiente, o como se dice, "ser entendido" en algo, no es lo mismo que ser consciente y pensante. Esta diferencia se traduce en una tensión que se expresa en el orden institucional. ¿La universidad tiene que cultivar la ciencia y la tecno-ciencia?

Sin duda que necesita hacerlo, pero esta necesidad, por imperativa que sea, no puede ser absorbente al punto de descuidar otros asuntos, no tan imperativos, pero ineludibles.

Por lo demás, la universidad no siempre ha sido el lugar único o exclusivo de la creación de la ciencia, tampoco lo es ahora. La ciencia espacial, por ejemplo,

4 Miguel Orellana "Origen y transfiguración de la universidad chilena entre 1622 y 2018 " (Inédito). 
se desarrolla de consuno con la exploración espacial y, al menos en Estados Unidos, aunque resulte sorprendente, la empresa privada invierte sumas siderales, valga la redundancia, en explorar Marte y el espacio estelar. No hay universidad que acometa proyectos de esa envergadura, y otro tanto ocurre con los observatorios astronómicos y sus telescopios gigantes: no son de carácter universitario.

Los primeros científicos modernos, como Descartes, Espinoza o Leibniz, no realizaron sus investigaciones dentro de una universidad; lo mismo puede afirmarse de Pascal, Hume, Locke o Voltaire. No siempre las nuevas ideas y los nuevos inventos surgieron en el marco de cátedras universitarias, y a veces fue al revés: las academias obstaculizaron los avances del saber ${ }^{5}$.

Hoy la situación es distinta, claro está, pero la mirada de largo plazo no es monopolio de nadie. El tiempo en el que un hombre de ciencia solitario, disponiendo de medios artesanales, y premunido tan solo de su ingenio podía realizar grandes proezas y descubrimientos, ya pasó. Pero ahora existe el riesgo inverso, y es que la ciencia y el saber derivado de ella, abarquen y consuman todo el esfuerzo de las academias. Ante eso, es preciso afirmar que "la universidad es distinta pero inseparable de la ciencia. Yo diría es, además, ciencia"'. En otras palabras, la universidad no puede existir sin ciencia, pero no puede convertirse en una institución solo científica (o solo tecnológica o solo profesional).

En este punto, permítanme evocar la experiencia que hicimos en el Centro de Estudios Humanísticos de la Facultad de Ciencias Físicas y Matemáticas de la Universidad de Chile. Tomaré este ejemplo, no porque sea ejemplar sino más bien para reflexionar sobre lo que allí se intentó. Un caso singular, en efecto, puede constituirse en regla y revestir, una función ejemplarizadora. En el derecho, la excepción adquiere rango de regla o, como se dice en jerga jurídica, "sienta jurisprudencia"; en el relato del paciente, lo más revelador a ojos del analista, es la escena omitida en el relato; esa experiencia borrada da la pista, como el tachado de un texto: muestra lo prohibido de lo querido; en fin, un ejemplo banal: un resto de ratón en una bebida no requiere de otro caso para suspender el consumo.

Lo que quiero decir es que ese intento de formar a los ingenieros en materias humanísticas no sienta jurisprudencia, pero en ningún caso fue como el residuo en la bebida. La necesidad de formación humanística en los ingenieros y en las profesiones, no fue en modo alguno una experiencia crucial y fallida. Está más vigente que nunca en el campo de las ingenierías, porque la tecnología no es solo un medio o instrumento de la productividad, es también una forma de normar el mundo. El argumento que resta competencia al especialista en virtud de que posee un saber local y parcial, es correcto, pero ingenuo y hasta peligroso: no tiene suficientemente en cuenta las transversalidades entre los saberes; tampoco considera la potenciación del poder sobre la naturaleza y la sociedad, que genera el conocimiento. La ingeniería es la práctica constructora

Jorge Millas, Idea y defensa de la universidad. Ediciones UDP, Santiago, 2012, p. 143. Op. cit., p. 120. 
por excelencia; como cualquier práctica humana, produce efectos no deseados, por eso reviste interés no solo para los especialistas. Las leyes dictadas al menos tienen lugar en cenáculos y parlamentos, donde se las establece a través de la discusión y el diálogo, pero el modo de pensar calculante despoja las prácticas profesionales de su significación pública y tiende a resaltar solo su significado instrumental, y reemplaza el sentido por la utilidad ${ }^{7}$.

Si a las humanidades se las cultiva por su valor intrínseco más que por su valor instrumental, con las ingenierías ocurre al revés, y su gran valor instrumental plantea la cuestión sobre si proponer a los ingenieros otros modos de pensar posee valor intrínseco, porque no se trata de superponer un deber ser a lo que es. Tampoco se trata, como se dice, de "descuadrar" a los ingenieros, como si tuvieran algo que redondearles. Es el ciudadano ingeniero el que ha de ser interpelado, más que un imaginario, inexistente, ingeniero "puro": eso es por lo menos lo que yo intenté cuando enseñábamos filosofía a los ingenieros. Pero la cuestión general es que las humanidades, la filosofía en particular, ha de evitar la tentación del ensimismamiento y la pretensión de autosuficiencia. Eso significa: abrirse a disciplinas afines, complementarias o colindantes; rehusar, por ejemplo, la idea que su "materia" es la historia de la filosofía. Si hay Centros de Estudios Humanísticos en Facultades que no son de humanidades, es porque hay cruces, entrelazamientos y requerimientos mutuos entre los saberes, no superposición ni imposición, más bien fecundación.

En la carrera de Ingeniería Comercial, la cosa era distinta, por lo menos, quienes elegíamos seguir la especialidad de "Economía" en lugar de "Administración", lo que teníamos en mente era la economía nacional. Se enseñaba mucho cálculo, trigonometría y estadística, pero la dimensión pública nunca estaba ausente en materias como Desarrollo económico, Política fiscal, Derecho del trabajo, Teoría monetaria, Comercio internacional, etc. No era pues cuestión de agregarle algo distinto al saber profesional, porque este ya de suyo remitía a un modo de pensar holístico. Y un ramo como Historia de las doctrinas económicas no podía dejar de plantear cuestiones filosóficas, justamente porque se trata de doctrinas, es decir, que no hay un solo modo de entender la economía: se supera el monologismo de la teoría y la pretensión de univocidad de la economía pura. Adam Smith, el fundador de la Economía Política, como se sabe, se desempeñaba en la cátedra de moral en la Universidad de Glasgow; y la nueva disciplina surgió, precisamente de la cuestión de la distribución de la riqueza. Uno no se arrepiente de haber estudiado economía, no porque la disciplina ayude a hacerse una idea de cómo funciona el mundo sino, sobre todo, forma la mirada y la sensibilidad para los asuntos públicos. Este ejemplo tiene ese significado: no es un elogio de los economistas sino una ejemplificación de que la formación profesional en su caso, procura -o puede procurar-elementos de los que carecen otras profesiones. Los

Marcos García de la Huerta y Carl Mitcham, La ética en la profesión de ingeniero. Ingeniería y ciudadania, DEH, Santiago, 2001. Carl Mitcham ¿Qué es la filosofía de la tecnología? (1989); Thinking Ethics in Technology. Division of Liberal Arts and International Studies. Colorado School of Mines, 1997; Engineering Ethics Toolkit (1998). 
ingenieros y tecnólogos los requieren más que nadie, porque su ideología espontánea tiende a omitir la normatividad implícita y los contra-efectos de su propia práctica. La idea de que la tecnología es neutra, porque solo es "ciencia aplicada", es la formulación más cruda y difundida de esta omisión.

Conocer el proceso de la toma de decisiones técnicas y el lugar que en él ocupa la consulta a los afectados, no es superfluo; permite evitar errores de diseño, de localización y de ejecución. Algunos de estos errores se los cita como ejemplos de fallas de ingeniería, y en parte lo son, pero con mayor frecuencia son resultado de licitaciones manipuladas, de decisiones ahorrativas - economías que cuestan caro- o de errores de ejecución. No hay tecnología democrática, es cierto, pero puede haber democracia en las decisiones técnicas, y a veces debe haberla porque afectan a todos.

No quisiera recargar más su atención; solo sintetizar estas palabras sobre la desconfianza / debilitamiento de las instituciones -lo que llamamos desinstitucionalización-, enfatizando que los comienzos son momentos de institucionalización y de identificación. En la creación de las universidades, tomamos a Andrés Bello como figura historial, es decir, de significado emblemático, permanente. Y enfatizamos el lugar de las humanidades en el espacio público, más allá de su valor intrínseco, por su contribución a la formación del profesional ciudadano, una figura no antitética a la del ciudadano profesional. La ingeniería en particular se asocia a la ciudadanía como práctica normativo-reguladora, aunque no dicte leyes, es el sujeto anónimo, invisible, que moviliza el creciente poder técnico. La cuestión general es que las humanidades, la filosofía en particular, deben evitar la tentación del ensimismamiento; esto significa apertura a disciplinas afines o complementarias, rehusar la idea que su "materia" es la historia de la filosofía; en fin, la necesidad de crear grados dobles con otras disciplinas o carreras, en virtud de los cruces entre ellas, por ejemplo, con Derecho, Ciencia Política, Estudios Latinoamericanos, Psicoanálisis, etc.

Muchas gracias 